\title{
ASSESSING THE SELF-DIRECTED LEARNING SKILLS OF THE UNDERGRADUATE NURSING STUDENTS IN A MEDICAL UNIVERSITY IN BAHRAIN: A QUANTITATIVE STUDY
}

\author{
Catherine Mary Abou-Zaid MSc(HCM), RGN, PGDip(Coun), PGDip(Pychol), \\ cabouzaid@rcsi-mub.com
}

\begin{abstract}
This quantitative study discusses the concerns with the self-directed learning (SDL) skills of the undergraduate nursing students in a medical university in Bahrain. The nursing undergraduate student SDL study was conducted taking all 4 years and compiling data collected from the students themselves by survey questionnaire. The aim of the study is to understand and change the attitudes of self-directed learning among the undergraduate students. The SDL of the undergraduate student nurses has been noticed to be lacking and motivation to actually perform without supervision while out-with classrooms are very low. Their use of the resources available on the virtual learning environment and also within the university is not as good as it should be for a university student at this level. They do not use them to their own advantage. They are not prepared for the transition from high school to an academic environment such as a university or college. For some students it is the first time in their academic lives that they have faced sharing a classroom with the opposite sex. For some this is a major issue and we as academics need to be aware of all issues that they come to higher education with.
\end{abstract}

Design Methodology: The design methodology that was chosen was a quantitative design using convenience sampling of the students who would be asked to complete survey questionnaire. This sampling method was chosen because of the time constraint. This was completed by the undergraduate students themselves while in class. The questionnaire was analyzed by the statistical package for social sciences (SPSS), the results interpreted by the researcher and the findings published in the paper. The analyzed data will also be reported on and from this information we as educators will be able to see the student's weaknesses regarding selfdirected learning. The aims and objectives of the research will be used as recommendations for the improvement of resources for the students to improve their SDL skills.

Conclusion: The results will be able to give the educators an insight to how we can change the self-directed learning techniques of the students and enable them to embrace the skills and to focus more on being self-directed in their studies rather than having to be put on to a SDL pathway from the educators themselves. This evidence will come from the analysis of the statistical data. It may even change the way in which the students are selected for the nursing programme. These recommendations will be reported to the head of school and also to the nursing faculty.

Keywords: Self-directed learning, Undergraduate Students, Transition, Statistical Package for Social Sciences (SPSS), Higher Education. 


\section{INTRODUCTION}

When entering into higher education the students have to be expected to be responsible for part of their own learning. The fact that higher education differs from high school is such that the students here in the Middle East are not academically or socially prepared for the experience. This gives us a major issue for concern and we as educators have to be prepared to deal with these issues. The demographics of university nursing students vary greatly and are continually changing globally. 'Understanding and updating our knowledge about the learning styles of undergraduate university and midwifery students are becoming increasingly important as the students become more and more diverse and are being taught using a large array of pedagogical approaches' (D'Amore et al., 2012, p. 506). 'Traditional pedagogical method of lecture may add relatively little to students' knowledge since it does not acknowledge individual differences and since it ignores the role of experience in knowledge formation, (Manolis, et al., 2013, p. 44).

\subsection{Adult Education}

Self-learning that is based on adult education is a process in which the initiative is at the individual and in which the individual determines his/her own learning necessities, aims and learning sources with or without help of others, as well as, he/she chooses appropriate learning strategies and evaluates learning results (Knowles, 1975, in Senyuva \& Kaya, 2014, p. 387).

Some of the students are transcending from Arabic taught curriculums to full English curriculums as we are in this University. So facing this language barrier along with other issues is something that the university is trying to deal with by delivering remedial classes in the English language. We are supplementing one major issue. Another major issue is that of self-directed learning. The students in the Middle East are mostly taught by memorizing rather than by rationalizing. This gives us as educators a major task of changing attitudes towards learning and bringing and developing new study habits. 'In a constantly changing environment, self-directed learning is essential for enabling nursing students to develop independent learning skills, and is a sense of accountability, responsibility and assertiveness that are essential attributes to the nurse's career', (Bastable, 2008, LevettJones, 2005, in El-Gilany \& Abusaad, 2012, p. 1040).

\subsection{Lifelong Learning}

Fostering lifelong learning among nursing students is a growing trend in nursing education, (Cheng et al., 2014, p. 90). We as educators are always and should be changing the way in which we deliver information and knowledge to our students. Quality education is under scrutiny in many countries today. Yarmohammadian, (2004), Yarmohammadian, Mozaffary, \& Saghaeiannejad Esfahani (2011) in Dorri et al., (2012) tell us that "Academic quality improvement in higher education has recently been considered in many universities over the world". This also refers to the art of self-directed learning that we as educators have to encourage and ensure that 
our students are gaining and building on this skill.

\section{UNDERSTANDING WHAT IS NEEDED}

Helping students get more out of their learning experience is a number one goal of teaching and training institutions, (Edmondson et al, 2012). We as educators need to understand the culture and learning types of our students. To do this we need to use pedagogical ways of teaching in order to keep up with epistemological evidences.

\section{DESIGN METHODOLOGY}

The quantitative study was chosen to get the most data in the shortest time. The convenience sample would give the researcher a more structured collection phase using a specific day and time for data collection.

A survey questionnaire was designed using the Liekert scale to assess certain attributes of the students. Closed questions were chosen for the study as they are easier to convert to numerical format required for the data analysis tool. As Pallant (2010, p. 8) tells us "Closed questions are usually quite easy to convert to the numerical format required for SPSS". The study questions in their entirety were designed to make it as easy as possible for the students to complete. Because of the clinical practice commitments of the undergraduate nursing students we would ask them to complete the questionnaire during their theory weeks in class during a specified time. An extra hour was added to the syllabus orientation for this task, this enabled the participating students to complete the questionnaire without feeling pressured.

\subsection{Ethical Considerations}

The students were given an overview of the study aims and objectives. An informed consent was signed by each agreeing participating student. Anonymity would be upheld at all stages in the study. Their right to withdraw from the study at anytime during the session with no actual comeback on their participatory rights was also explained during the orientation. They were also given the right to refusal to commence in the study from the beginning. 'Consent generally is expressed or implied. Express consent can be an oral declaration of consent or it can be provided by printed words in a written consent form (usually called informed consent)', (Rock \& Hoebeke, 2014, p. 189). Time was given for questions from the students. The consent form was signed and the questionnaire was completed and collected by the researcher within the specified time.

\subsection{Data Collection}

Data was collected on the questionnaire by asking question on the following using the following headings: Demographic data, self management, directed learning, desire to learn and time management. The convenience sample was that of the respondents being able to fill the survey questionnaire when and where they wanted although time was set aside for this specific task.

The convenience sample was drawn from the undergraduate student nurses in the 
researchers own university and came from the first, second, third and fourth year cohorts within the Kingdom of Bahrain. The undergraduate student response was that of 71 out of a cohort of 400 registered with the university.

The demographic data consisted of 5 variables: age, gender, schooling (either private or governmental), and fees either sponsorship or self funding, and nationality. These variables would give the researcher an idea of the background and ages of the students and whether or not the schooling or sponsorship has an impact on their views and attitudes towards SDL.

The survey questionnaire was developed using the Liekert scale as a guiding force. The questions were developed with the background of the majority of undergraduate students in mind and took into consideration their background including their particular area of schooling. The questions concentrated on their time management skills and their desire to learn. The scale was from 1-5 for scoring with 5 being excellent.

\subsection{Data Analysis}

Data analysis would be undertaken using the Statistical Package for Social Sciences (SPSS) version 22. This would give two different views of the data, data view and variable view. After labeling the different concepts, we would move to the descriptive statistics. In the descriptive statistics we can get the numerical variables and categorical variables. This will give us the indication of any significant differences in the categories.

\section{RESULTS OF THE DATA ANALYSIS}

The findings from the SPSS analysis showed that the variables were analyzed and the characteristics charted. These variables were analyzed to discover the actual trends of the undergraduate students and their assumptions of SDL. The variables were listed as follows: gender, schooling, nationality, sponsorship, time management skills, desire to learn and self control.

\section{PERSONNEL CHARACTERISTICS}

A total of 4 variables were analyzed to describe the participant's demographic characteristics. These variables were analyzed to enable the researcher to gain information regarding the personal characteristics of the undergraduate student nurses in the study.

The table shown in Figure 1 shows the demographic data which includes; gender, schooling, country of residence and how fees are paid, this table will be used to understand and see any significant attributes leading to the recommendations that may be needed for change and to help the students understand the concepts of SDL.

The dataset will be explained by using the demographic concepts of the study, with $n$ being $=71$ the number of students who completed the survey questionnaire. See Figure 2. 
Figure 1. Demographic Data Collection.

\begin{tabular}{|c|c|c|c|c|c|c|c|c|c|c|c|c|c|c|c|c|}
\hline & & \multicolumn{5}{|c|}{ Total self management } & \multicolumn{5}{|c|}{ Total Desire to learn score } & \multicolumn{5}{|c|}{ Total Self-control score } \\
\hline & & \multirow[t]{2}{*}{ Mean } & \multirow[t]{2}{*}{$\begin{array}{c}\text { Mean } \\
\text { Difference }\end{array}$} & \multicolumn{2}{|c|}{$\begin{array}{l}95 \% \text { Confidence } \\
\text { Interval of the } \\
\text { Difference }\end{array}$} & \multirow[t]{2}{*}{$\begin{array}{c}\mathrm{P} \\
\text { value }\end{array}$} & \multirow[t]{2}{*}{ Mean } & \multirow[t]{2}{*}{$\begin{array}{c}\text { Mean } \\
\text { Difference }\end{array}$} & \multicolumn{2}{|c|}{$\begin{array}{l}95 \% \text { Confidence } \\
\text { Interval of the } \\
\text { Difference }\end{array}$} & \multirow[t]{2}{*}{$\begin{array}{c}\mathrm{P} \\
\text { value }\end{array}$} & \multirow[t]{2}{*}{ Mean } & \multirow[t]{2}{*}{$\begin{array}{c}\text { Mean } \\
\text { Difference }\end{array}$} & \multicolumn{2}{|c|}{$\begin{array}{l}95 \% \text { Confidence } \\
\text { Interval of the } \\
\text { Difference }\end{array}$} & \multirow[t]{2}{*}{$\begin{array}{c}\mathrm{P} \\
\text { value }\end{array}$} \\
\hline & & & & Lower & Upper & & & & Lower & Upper & & & & Lower & Upper & \\
\hline \multirow{2}{*}{ Gender } & Male & 31.25 & \multirow{2}{*}{-0.65} & \multirow{2}{*}{-4.09} & \multirow{2}{*}{2.78} & \multirow{2}{*}{0.70} & 27.75 & \multirow{2}{*}{-3.84} & \multirow{2}{*}{-7.93} & \multirow{2}{*}{0.25} & \multirow{2}{*}{0.07} & $\mathrm{Sc}$ & \multirow{2}{*}{1.74} & \multirow{2}{*}{-3.34} & \multirow{2}{*}{6.82} & \multirow{2}{*}{0.50} \\
\hline & Female & 31.90 & & & & & 31.59 & & & & & 38.38 & & & & \\
\hline \multirow[b]{2}{*}{ School } & Government & 31.91 & \multirow[b]{2}{*}{0.76} & \multirow[b]{2}{*}{-1.49} & \multirow[b]{2}{*}{3.02} & \multirow[b]{2}{*}{0.48} & 30.84 & \multirow[b]{2}{*}{-3.16} & \multirow[b]{2}{*}{-7.54} & & & 38.08 & & & & \\
\hline & Private & 31.14 & & & & & 34.00 & & & 1.22 & 0.16 & 43.14 & -5.06 & -10.33 & 0.20 & 0.059 \\
\hline & & & & & & & & & & & & & & & & \\
\hline Country & Bahrain & 31.88 & & & & & 30.85 & & & & & 38.09 & & & & \\
\hline $\begin{array}{l}\text { of } \\
\text { Residence }\end{array}$ & $\begin{array}{l}\text { Non } \\
\text { Bahraini } \\
\end{array}$ & 31.33 & 0.54 & -3.36 & 4.45 & 0.78 & 34.50 & -3.65 & -8.34 & 1.03 & 0.12 & 43.83 & -5.74 & -11.37 & -0.11 & 0.046 \\
\hline & Sponsored & 31.95 & & & & & & & & & & 3809 & & & & \\
\hline $\begin{array}{l}\text { How are } \\
\text { fees paid }\end{array}$ & Self funded & 30.50 & 1.45 & -2.44 & 5.34 & 0.46 & $\begin{array}{l}30.00 \\
34.33\end{array}$ & -3.47 & -8.16 & 1.22 & 0.14 & $\frac{50.09}{43.83}$ & -5.74 & -11.37 & -0.11 & .046 \\
\hline
\end{tabular}


Figure 2. Exploring the data using frequency analysis.

Statistics

\begin{tabular}{|cc|r|r|r|r|r|}
\hline & & \multicolumn{1}{|c|}{$\begin{array}{c}\text { Student } \\
\text { identification }\end{array}$} & Gender & $\begin{array}{c}\text { Secondary } \\
\text { School }\end{array}$ & $\begin{array}{c}\text { Country of } \\
\text { Residence }\end{array}$ & $\begin{array}{c}\text { How are fees } \\
\text { paid }\end{array}$ \\
\hline N & Valid & 71 & 71 & 71 & 71 & 71 \\
& Missing & 0 & 0 & 0 & 0 & 0 \\
\hline
\end{tabular}

6. GENDER, SCHOOLING, COUNTRY OF RESIDENCE AND HOW FEES ARE PAID? (TOTAL SELF MANAGEMENT)

\subsection{Gender}

In the

Total self management (TSM) showed a $p$ value of 0.70 for both male and female. The mean difference showed -0.65 , the $95 \%$ confidence interval (CI) of the difference showed a lower limit (LL) of 4.09 and an upper limit (UL) of 2.78 and the mean for females were 31.90 and for males 31.25. The difference in the total self management was not significant to their SDL skills.

\subsubsection{School}

The $p$ value of TSM was 0.48 . This showed no actual significant difference in the way in which the students where schooled before coming to the university. The mean difference was 0.76 ; the mean for government school was 31 and for private schools was 31.14, The 95\% confidence interval of the difference showed; lower level of -1.49 and upper limit of 3.02 .

The mean for students coming government school was 31.91 and for private school students 31.14 giving no significant difference in the schooling having impact on SDL skills.

\subsubsection{Country of Residence}

The TSM showed that the $\mathrm{p}$ value was 0.78 for Bahraini and non-Bahraini. The mean difference showed 0.54 with the actual mean for Bahraini $=31.88$ and for non Bahraini $=31.33$, the $95 \% \mathrm{CI} ; \mathrm{LL}=-3.36$ and $\mathrm{UL}=4.45$. The results for country of residence showed no significant difference in the SDL.

\subsubsection{How are Fees Paid?}

The TSM showed that the $\mathrm{p}$ value was 0.46 for sponsored and self-funded students. The mean difference was 1.45 showing that the $95 \%$ of $\mathrm{CL} ; \mathrm{LL}=-2.44$ and $\mathrm{UL}=5.34$ with the actual mean for sponsored $=31.95$ and self-funded $=30.50$. The results for sponsored and self-funded showed no actual significance in the SDL.

\subsection{Total Desire to Learn}

Total desire to learn (DTL) showed a $\mathrm{p}$ value of 0.007 . This score was very low 
and showed that there was a significant difference in the students desire to learn. The actual mean for female students was 31.59 and for male students were 27.75 , giving us the mean difference of -3.84 . The ' $95 \%$ confidence interval of the difference' showed a lower limit of -7.93 and an upper limit of 0.25 . Therefore gender in desire to learn shows that there was a significant difference in the desire to learn. This statistical evidence gives the female students more desire to learn than the male students.

\subsection{Total Self-control}

The students self control (TSC) in their SDL showed a $p$ value of 0.50 . This indicates that there is a significant difference in the self control of SDL skills. The mean for female students was 40.13 for male students and 38.38 for female students. The mean difference is 1.74 . The male students have more self control than female students. The ' $95 \%$ confidence interval of the difference' showed a lower limit of -3.32 and an upper limit of 6.28. The statistical evidence shows that there is no significant difference between the male and female students.

\subsection{Validity and Reliability}

Pallant, (2010), p. 6) states that "The reliability of a scale indicates how free it is from random error and the validity of a scale refers to the degree to which it measures what it is supposed to measure".

\subsection{Discussion.}

In this study we are looking at the student's behavior and from which 'type' of background they are coming from. We can see that the significant difference in the statistical results show that the 'desire to learn' shows a $\mathrm{p}$ value of 0.007 which indicates that there is a difference in the students desire to learn and females have more desire to learn than males. There is also a significant difference in the 'total self control' of students coming from private institution compared with the students who come from governmental institutions, showing that the private students show selfcontrol than governmental students.

Students who were non Bahraini showed more 'self-control' than Bahraini students showing a significant difference in the $\mathrm{p}$ value (0.046). Showing a mean of 38.09 for Bahraini and 43.83 for Non Bahraini. Self funded students showed a mean of 43.83 and sponsored students showed a mean of 38.09 with a $p$ value of .046 which indicated that the self funded students have more self-control on SDL than sponsored students.

\section{IMPLICATIONS OF THE STUDY ON THE UNDERGRADUATE STUDENTS}

Implications on the SDL of the undergraduate nursing students can be seen as a 'message' that can be 'turned' around in order to be able to motivate the students to be able to take responsibility for their own learning. We as educators have to be able to, at an early stage, make the students understand the need for SDL skills and how they can be developed. Making SDL skills part of the curriculum is one way in which the topic can be integrated to the already existing teaching and learning category. The 
results have no specific bearing on the student's academic work and will not be taken as a personal attribute on the students who took part in the SDL study.

\section{RECOMMENDATIONS}

Implications for change in our delivery system and adding SDL skills to the curriculum would enable students to understand the need for their SDL development. Using the development of practical nursing skills as a base for the SDL skills would enhance the student's ability to conform to their practice. Increasing more blended learning techniques as well as encouraging online collaborations would bring the students closer together and this would encourage SDL as a team.

\section{CONCLUSION}

Undergraduate nursing students are now looking forward to expanding their careers and have to be able to look at teaching and learning as a way to enhance their own SDL skills. Educators need to be trained to notice changes in learning techniques and be able to introduce new technologies and delivery systems to the curriculum. Looking at ways to increase the need for SDL skills to be taught to the students has to be a priority in the delivery systems.

\section{ACKNOWLEDGEMENTS}

Thanks to all the undergraduate nursing students from The Royal College of Surgeons in Ireland-Bahrain, who gave their time and consent to take part in this study.
The support of the Dean of the School of Nursing and the President of RCSI-Bahrain is also highly appreciated. A special thank you to Dr. Khalifa El Musharraf who assisted in the SPSS analysis. 


\section{REFERENCES}

D'Amore, A., James, S., \& Mitchell, E., K., L., (2012). 'Learning styles of firstyear undergraduate nursing and midwifery students: A cross-sectional survey utilising the Kolb Learning Style Inventory', Nurse Education Today, 32, pp. 506-515.Available at: http://www.elsevier.com. (Accessed on: 12 December 2014).

Edmondson, D., R., Boyer, S., L., \& Artis, A., B., (2012). 'Self-Directed Learning: A meta-Analytic Review of Adult Learning Constructs'. International Journal of Education Research, Volume 7, (1), pp. 40-48.

El-Gilany, A-H., \& Abusaad, F., E., S., (2012). 'Self-directed learning readiness and learning styles among Saudi undergraduate nursing students', Nurse Education Today, 33, pp. 1040-1044.

Manolis, C., Burns, D., J., Assudani, R., \& Chinta, R., (2013). 'Assessing experiential learning styles: A methodological reconstruction and validation of the Kolb Learning Style Inventory', Learning and Individual Differences, 23, pp. 44-52. Available at: http://www.elsevier.com/locate/lindif.com. (Accessed on: 4 December 2014).

Pallant, J., (2010). SPSS Survival Manual. $4^{\text {th }}$ ed., Open University Press, New York, USA.

Chengl, S-F., Lee-Hsieh, J., Turton, M., A., \& Lin., K-C., (2014). 'Validation of Self-Directed Learning Instrument and
Establishment of Normative Data for Nursing Students in Taiwan: Using Polytomous Item Response Theory', the Journal of Nursing Research, 22(2), pp. 90100.

Rock, M., J., \& Hoebeke, R., (2014). Informed Consent: Whose Duty to Inform? MedSurg Nuring, 23(3), pp. 189-192.

Senyuva, E., \& Kaya, H., (2014).' 'Effect self directed learning readiness of nursing students of the web based learning, Procedia - Social and Behavioral Sciences 152(3), pp.8-392. 